Kiemle-Gabbay L \& Lavallee D (2017) Coping in High-Risk Snow-Sports: A Qualitative Exploration of Alpine Racing and Freestyle Athletes' Experiences, accepted for publication in Journal of Loss and Trauma by Taylor and Francis. https://doi.org/10.1080/15325024.2017.1284517 
1 Coping in High-Risk Snow-Sports: A Qualitative Exploration of Alpine Racing and Freestyle

2

3

4

5

6

7 This study examines how semi-elite student snow-sport athletes utilise process and trait

8 coping strategies to combat risk-taking, potential loss and trauma, and other stressors integral

9 to their sport participation. Factors influencing coping strategy preference are also explored.

10 Semi-structured interviews were used to explore ten participants' experiences; the narratives

11 were analysed using thematic analysis. Five master themes emerged from the analysis:

12 Challenges to Overcome; Taking Action; Changing Perspectives; Staying in Control; and 
Coping in High-Risk Snow-Sports: A Qualitative Exploration of Alpine Racing and Freestyle Athletes' Experiences

Two prominent definitions of psychological coping exist within scientific literature;

the process and trait approaches. The process approach assumes individuals approach coping situations dynamically, thus constantly adjusting their cognitive and behavioural efforts to manage specific demands appraised as stressful, and these efforts are situation-dependent (Lazarus \& Folkman, 1984). Conversely, the trait approach suggests individuals do not approach every coping situation anew, but utilise a preferred set of coping strategies (or styles) which remain relatively fixed (Carver, Scheier \& Weintraub, 1989). Coping styles aim to change or reduce stressors, or manage the emotional responses elicited as a result (Lazarus \& Folkman, 1984).

Loss has been broadly defined by Harvey (1996) as a reduction in personal, material and/or symbolic resources. Athletes may experience losses throughout their sporting career, for example; after losing competitions, retiring from sport or during periods of injury or performance slumps (Lavallee, Grove, Gordon \& Ford, 1998). These losses may result in athletes experiencing physical and/or psychological trauma, which may require the utilisation of coping behaviours. For high-risk sport athletes, such as those competing in alpine snowsports, the consequences of their risk-taking behaviour is more likely to result in loss and/or trauma to the athlete, due to the fine margins of error with potentially serious consequences, leading to a higher frequency of such incidents (Flørenes et al., 2009).

Folkman and Lazarus' (1980, 1985) 'Ways of Coping Scale' defines two distinct dimensions of process coping. Problem-Focused Coping (PFC) describes task-orientated coping efforts and Emotion-Focused Coping (EFC) aims to reduce emotional stress associated with a situation. A third dimension, Avoidance-Focused Coping (AFC) was later developed by Endler and Parker (1990) and relates to coping efforts aimed at ignoring or 
1 avoiding stressors. Carver et al., (1989) believed the 'Ways of Coping Scale' (Folkman \&

2 Lazarus, 1980; 1985) to be an overly simplistic measure with insufficient grounding in

3 theoretical understanding, and contradictory to the trait approach of coping. Thus, they

4 developed the COPE Inventory, an instrument measuring 13 conceptually distinct coping

$5 \quad$ strategies derived from theoretical understanding (see Carver et al., 1989; Lazarus \&

6 Folkman, 1984). Both the COPE Inventory and its revisions (Zuckerman \& Gagne, 2003)

7 have been adapted and applied to research within sports psychology, and may be used to

8 identify which coping strategies are being utilised by athletes.

Athletes require strategies to cope with the everyday stressors of sporting life, such as injury, conflict with coaches, performance anxiety and results compared to expectations. Nicholls and Polmon's (2007) systematic review of coping in sport suggested athletes who cope poorly with stress may suffer significant performance failures. Thus, the adoption of successful coping strategies should ensure more enjoyable and rewarding sport participation (Lazarus, 2000). The majority of studies reviewed by Nicholls and Polman (2007) concerned athletes from low-risk sports (e.g. golf, athletics, ball/racket sports).Whilst most athletes may at some stage be required to utilise coping strategies to combat stress related to their sport participation, the stressors facing the majority of the athletes from their review did not include concerns regarding life-threatening injuries or death. For high-risk sport athletes, the use of coping strategies may be more frequent, to ensure effective management of potential physical and psychological consequences resulting from the high-risk behaviours integral to their sport.

Celsi (1992) suggested some high-risk sports such as mountain climbing and skydiving may be understood as transcendent experiences, as participants risk severe injury or death engaging in the sport. Celsi, Rose \& Leigh (1993) defined feelings commonly described by high-risk sport athletes, such as experiencing altered temporal states (e.g. a 
1 feeling of 'timelessness') or a sense of camaraderie with others as belonging to this

2 'transcendent experience', thus acting as a form of psychological reward. High-performance skiers and snowboarders from both freestyle and racing snow-sport disciplines knowingly risk injury and even death, and may use the perceived psychological benefits of the transcendent experience associated with high-risk sport participation as a coping strategy.

6 However, currently no research has explored this. Competitive skiing and snowboarding at an elite, or semi-elite level, does not come without risks. After conducting interviews with 521 World Cup (WC) ski racers during the 2006-7/2007-8 competitive winter seasons, Flørenes et al., (2009) found $28 \%$ of the WC alpine, freestyle and cross-country skiers interviewed had suffered at least one 'severe injury' (requiring more than 28 days absence from training for recovery). Subsequently, it was suggested the number of severe injuries acquired by alpine, freestyle and snowboard athletes is considerably higher compared to most other sports (Flørenes et al. 2012). Rotella et al.'s (1980) report found performance benefits for elite alpine racers who adopted variations of PFC-focused strategies within their skiing; thus there is some evidence suggesting snowsports athletes both require and utilise coping strategies. However, the study suffers from a number of limitations. Alpine racing has changed drastically since the 1980s, including significant advances in equipment and increases in speed associated with elevated technical, physical and potentially psychological demands required of the athletes. Furthermore, Rotella et al.'s (1980) study predates the emergence of competitive snowboarding or freestyle. Subsequently, there is a scarcity of research, particularly more recent empirical evidence, related to coping strategies utilised by competitive snow-sport athletes. Whilst a substantial amount of research has been conducted into how individuals in high-risk occupations (e.g. military, emergency services personal) utilise coping strategies, much of this relates to coping after a traumatic experience (Bonanno, 2004). High-risk sport 
1 athletes, including snow-sport athletes, cope with risk as an ever-present stressor during

2 training and competing; their experience of stress is not limited to post-injury trauma,

3 although little is currently known as to how these athletes experience and prepare for risk-

4 taking.

5

Whilst alpine ski racing has a long and well documented history dating back to the early 1900s, competitive freestyle skiing and snowboarding first emerged during the late 1970s as a rejection of typical alpine skills. Currently, ski/snowboard freestyle is a collective term, commonly referring to the 'alternative' competitive disciplines of snow-sports, such as mogul skiing, slope-style (where ski/snowboard athletes complete a trick-course containing a number of obstacles including jumps, rails and boxes) and free-ride (competitive off-piste skiing/snowboarding). Despite the differences between these two branches of snow-sports, the potential consequences of the risk-taking required by its athletes remain the same. A serious crash in a high-speed alpine race can be just as dangerous (and potentially fatal) as a poor landing in freestyle; therefore, both may require the use of psychological coping strategies as part of the athletes' preparation prior to engagement. However, previous research such as Rotella et al. (1980) neglected to include freestyle athletes; therefore, this remains a largely unexplored research area and population, lacking up-to-date research.

The intention of this study is to expand upon the current literature by using qualitative methods to explore in depth the strategies utilised for coping with risk and other sources of stress within a student snow-sport athlete population. The pre-existing literature on coping in sport often neglects high-risk sport, and prior research on coping in snow-sports pre-dates freestyle and may no longer be relevant to alpine racing after advances in the sport. The adoption of an open, exploratory approach should allow for a thorough investigation into the experiences of coping with risk-taking within competitive snow-sports, across both alpine racing and ski/snowboard freestyle. 
The research aims of the current study were as follows; firstly to identify which aspects of snow-sports the athletes perceive as being high-risk and potential sources of stress. Secondly, to explore which coping strategies may be being utilised by the student snow-sport athletes sample, and the manner in which they are using them, to prepare for risk and other stressors within competitive snow-sports.

Methods

\section{Eligibility Criteria}

To be considered eligible for participation, athletes were required to be of a 'semielite' competitive status within the British and Scottish university snow-sports competition circuit. This was defined as having finished within the top 10 at a Scottish, or top 20 at a British university competition, within the last three years. Athletes who had competed or were currently taking part in national and/or international level competitions outside of the university circuit were also eligible to participate.

\section{Participants}

Ten student snow-sport athletes (five male, five female) participated in the study, following ethical approval. Ages ranged from $18-24$ (mean age $=21.2)$ with all currently attending a Scottish university. The participant sample comprised seven skiers and three snowboarders. Pseudonyms have been used throughout to ensure anonymity.

\section{Procedure}

Athletes from each university snow-sport society, who were identified as meeting the eligibility requirements, were invited to participate. Twelve potential participants were identified; however, for the purpose of the present study, theoretical saturation (Sparkes \& Smith, 2013) was reached after ten interviews, following which data collection was deemed complete. After obtaining informed consent, all semi-structured interviews were conducted on participants' own campuses. 
Measures

The interview schedule was designed to explore the research questions. For example, the question 'What stressors do you feel are a part of your sport?' related to the research question; which aspects of snow-sport participation do the athletes perceive as being highrisk/stressful? 'How do you approach a race course/run in the park?' aimed to explore which coping strategies were used by participants during their preparation. Questions that asked for participants to provide examples, e.g. 'Can you tell me about times when you felt you had to cope with a high level of stress or risk in your sport? What sorts of things did you do before, during and after the stressful event in order to cope with it?' required participants to describe how they had utilised their preferred coping strategies. Interview duration ranged between 20 -53 minutes (mean $=32$ minutes, $\mathrm{SD}=11.24)$ and were recorded with participants' consent, then transcribed verbatim by the author.

Analysis

Thematic analysis was conducted according to recommendations by Braun and Clarke (2006). An inductive analytical approach was taken, so that emerging themes would relate to the data itself and avoid being theoretically driven. Phenomenological and psychosocial perspectives were applied during the analysis, to uncover themes relating to both participants' experiences and their own psychological development. Each transcript was individually coded in NVivo (Bazeley \& Jackson, 2013). Codes from all ten transcripts were then organised into clusters, grouped into emerging themes and subjected to review.

Results

Four master themes related to the research questions were identified, including:

Challenges to Overcome; Taking Action; Changing Perspectives; and Staying in Control. Upon conducting the interviews, it became apparent the exploratory nature of the interview schedule allowed participants to provide responses relating not only to how they coped with 
1 risk/stress and what strategies they used, but also why they displayed a preference for certain

2 strategies over others. Subsequently, a fifth theme emerged, Underlying Influences.

3 Challenges to Overcome (see Table 1).

The first master theme refers to sources of stress, including risks identified by the

5 athletes during the interviews. Thus, it relates to the first research question; which aspects of

6 snow-sport participation do athletes identify as high-risk and/or stressful?

$7 \quad$ The Uncontrollable Elements

8

The majority of the athletes described how facing that which is uncontrollable often increased their perception of the risks involved. Variations in terrain and adverse weather conditions were highlighted as being significant causes for concern, due to their uncontrollable nature; 'In Scotland I'm quite cautious because... the temperature here can fluctuate so much... and it's not a big deep set of snow, it's often quite shallow snow and horrible rocks, so I think about it quite a bit more' (Ollie; pseudonyms used throughout).

Cara, like many of the athletes, emphasised the increased risk when attempting something new; 'whenever I go into a track and it looks completely different, I get a bit freaked out... because I know it'll feel completely different'.

Freddie described how new environments where the terrain varies from the familiar heightened his perception of risk: "So I guess going to new places especially if you're abroad with just... much bigger jumps or different snow conditions that is... that's a big risk because y'know [sic] say for example it's icy, it's dead fast, if it's slushy it can go dead slow and both can be equally dangerous."

\section{The Opinions of Others}

Many of the athletes described feeling under pressure to achieve good competitive results, so as to meet other people's expectations of their ability; 'I guess in a... competition itself, it's erm, it can be stressful to try and get results, you feel under pressure to perform, 
1 you don't want to disappoint yourself and your teammates' (Freddie). Ollie and Daisy's

2 concerns regarding the opinions of others outweighed personal injury-related anxieties:

“When I'm doing race or duals I worry... I don't worry about like... the risks of like slipping out and smashing myself. I worry because it's a team thing, and I always think about how... I don't wanna [sic] mess it up for the other people involved (Ollie)."

A general consensus was that racers (in particular ski racers), tended to be resultsfocused and 'serious'. Heather reported how adopting a less serious approach to ski-racing, which she perceived as being against the social norm for alpine racers, became a significant source of stress for her: "some people take it a lot more seriously and then they can kind of try and make you feel bad and stuff and it can get quite catty."

Injury and Injury Recovery

All participants expressed concerns related to the risk of injuring themselves or others whilst participating in snow-sports. Whilst most had experienced injuries they identified as being 'nothing particularly major' (Sam), often these transpired to be fractures or concussions. For athletes whose injuries were more severe, the potential consequences were a significant source of anxiety: "As soon as I hit my head everything went white, and my ears were ringing. I couldn't move anything in my body, which sucked. I was lying there... and I thought I'd broken my back, or like... done something that was paralysing (Ollie).",

For Freddie and Sam, losing potential skiing time to recovery was just as anxietyinducing as the risk of injury itself, with Sam explaining how being out for the season with an injury would "really suck 'cause I really love doing it". Ollie described frustration at having to "build myself back up to where I was" after losing freestyle skills acquired pre-injury to the recovery process. 
Anya emphasised the difficulties she faced in sacrificing experiences in other aspects

2 of life to further her racing career@ "I have given up so much for skiing. It's the whole... not going out to this party, not hanging out with friends at this point, skipping all sorts of weekend trips because I would go up to the mountains". Balancing academic pressures with

5 training/competitions had been a cause of conflict with her coach. Ben explained his decision

6 to focus on university over his racing career as being due to his unwillingness to take " $a$

7 future risk, of missing out on university, missing out on that opportunity... to risk it all... just

8 to go and ski race”.

$9 \quad$ Taking Action

The second theme referred to which coping strategies participants utilised to cope with risk and stress in snow-sports, and the limitations of these strategies. Although Holding Back is an example of an AFC strategy, choosing not to act is active in itself (Carver et al., 1989); thus, it was included in the Taking Action master theme.

\section{Cognitive and Behavioural Strategies}

Several of the freestyle athletes cited the merits of preparing 'back-up runs' they could switch to, were they to under/over-rotate in competition and be required to adjust. Freddie emphasised how developing a 'contingency plan' enables him to 'try and kind of prepare... for as many situations as possible. So I have options'. Cara explained how she is 'always thinking about the worst case that could happen', to prepare for the 'negative consequences', with her showing particular preference for this strategy when she felt out of control. After having learnt from his experiences of being caught in avalanches, Ollie now feels 'often I'll plan better, I'll think about why... how I'm going into things, how I'm going to tackle things and... if something did happen, what I'd do or where I'd go'. For Ben, 'ski racing was always just about trying to be as organised as possible'. His and Anya's planning strategies related to ensuring their equipment preparation was completed the day before 
1 competition to reduce stress.

Many of the racers found mental imagery rehearsal to be a useful cognitive strategy in competition; 'during course-inspection and stuff I would always try and like actually like picture the line and stuff and think about the course and think about where the combinations were' (Heather). Ben described mentally rehearsing specific corners of a downhill course so as not to be 'quite as surprised' when he skied them later. Movement visualisation was a common strategy amongst the freestyle athletes, often combined with watching videos of pro athletes performing tricks: "I'd say probably before I do heats in freestyle I visualise the trick being (pause) as if it's the video, as if it's that person doing it and y'know, like they've done it and that's how you'd do it, but then also... like visualising like myself doing it cause then, so first of all I get it in my head that that's how you do it and then I see like, myself going for it. (Jade)". Whereas freestylers reported using movement visualisation and imagery-rehearsal during preparation some weeks before the stressful event (e.g., trying a new trick); racers only utilised these strategies immediately before racing.

The final behavioral strategy referred to the group actively practicing their snowsports skills prior to competition. Max explained how acquiring a 'base of tricks that I can do really well' and rehearsing them prior to competition improved his confidence; 'I can tell myself those are the ones that I've practiced a lot recently, I know that I've got them fairly solidly.' Whilst most practicing took place within a snow-sport setting, Freddie discussed the merits of practicing movement off-snow, describing his process of 'trying to watch videos, trying stuff on the bedroom floor, trying to kind of go through positions that I need to be in'. Working with Others

Whilst the ski racers discussed working alongside coaches to improve performance, for the freestylers, skill development often occurred in an informal 'friendship group' environment. Sam discussed the transition from his introductory freestyle lessons to 'just like 
1 you and your friends helping each other out', and how skiing amongst his friends who were

2 pro-skiers allowed him to 'model' his speed and technique from observing them. For Freddie,

3 working as part of a group allowed him to learn from others by asking advice; 'you get

4 people who are really good at giving instructions and teaching, and if someone's kind of

5 good and explains stuff well it actually really helps'. Cara found snowboarding with friends

6 encouraged her to take more risks in her sport: "I guess I've become slightly more willing to

7 take risks, because of the kind of camaraderie of the ski club... the uni ski club's quite

$8 \quad$ y'know, it's quite a peer pressure thing I guess... so I'm kinda more pressured into taking

9 risks and to push boundaries". Daisy stated 'having other people there is amazing for

10 pushing you', and found having others who believed in her ability increased her confidence,

11 resulting in her attempting tricks she had previously never considered.

Avoidant Strategies

Several from the group described situations where they felt they had deliberately 'held

back' in their performance to cope with risk better. For Ben, this meant being reluctant to ski at his top speed whilst competing in Norway, as he felt the steeper and narrower slopes there increased his anxiety. Freddie described 'putting off' trying new tricks on holiday until the last few days to ensure he had 'less to lose', were he to fail in his attempts. After experiencing crashes or poor performance, Jade reported she would 'step it back to like being at less risk [...] and then just build it up'. This 'building blocks approach' was also used by Daisy and Max, who emphasised the need to restrain oneself from attempting too much too soon and instead preferred to 'gradually build it up' (Daisy).

Limitations of Strategies

Several of the group suggested they only initiated coping strategies after a negative incident had occurred, with some of the freestylers incurring injuries after performing tricks they were confident in. Ollie stated he felt his anxiety related to potential consequences of his 
1 risk taking diminished in periods where he felt confident in his snowboarding, which had on

2 occasion lulled him into a 'false sense of security'; 'if everything's going good every time you

3 go out, then there's no need to think about the risks [...] because if everything is going well

4 for you, why would the risks matter?' For Sam, the ability to utilise a coping strategy came

5 after skill execution, not before, rendering him unable to prepare for risk until after he had

6 taken it. Cara described incidents where despite having employed planning and imagery

7 rehearsal strategies in competition after a fall to prepare for her second run, ruminating on her

8 anxieties led to a repetition of her earlier mistakes, thus resulting in a 'self-fulfilling

9 prophecy'. She described how she therefore now avoids traditional aspects of on-snow

10 preparation (e.g. course-inspection) as she feels she has proved 'when I over-think things, I

11 just don't do them well'.

Changing Perspectives

The theme; Changing Perspectives refers to the athletes' use of strategies that aim to deliberately alter their mental attitude, so as to see things in a different, less stressful light.

Like Theme two, it relates to the research questions concerned with which strategies

participants utilise, and how they use them to better cope with risk and other stressors.

Accepting Risk as 'Normal'

All participants agreed that frequently confronting high-risk was integral to snowsport participation. For the racers, extreme speeds and risk-taking in alpine racing was considered typical, with Heather describing confronting high-risks as being 'almost like second-nature', attributing her lack of anxiety to her expertise. Daisy expressed how risk in freestyle is simply 'part and parcel of it' and that 'in freestyle you expect to fall [...] it's just the nature of it'. For her, the risk of injury was acceptable, as it went hand-in-hand with skill progression. Ollie believed freestylers may become initially attracted to the sport due to an innate ability to challenge and 'overcome those risks very quickly', stating that 'the people 
1 who take the bigger risks are the ones who do better'. Whilst in competition, Anya described

2 deliberate cognitive attempts to reduce risk through imagining the race 'as if it's just another

3 training day', as this allowed her to 'convince myself that it's normal'.

$4 \quad$ Staying Positive

5

Positive self-talk was used as a coping strategy by many of the athletes. Cara repeated a mantra of 'it will be fine, it will be fine' to herself when she felt most at risk, and Freddie emphasised a need to 'be logical' and not let his emotions take over. Anya used self-talk both to reduce anxiety and inform technique, a strategy also utilised by Ollie: 'I was just like, just relax... and don't blast it down because it's better to have a smooth one and not fall and miss a gate than to... do that'.

Daisy, Anya and Max all discussed using music to alter their frame of mind, but the purpose differed. For Max and Anya, music was used as a motivator; 'to kind of get me a bit more pumped up in the zone' (Max). However Daisy listened to music to 'zone out of the people around me' in competition. Meditation and relaxation are integral to Daisy's preparation during competition as she finds them more 'mentally challenging'.

For Daisy, staying positive expresses itself as being more mentally present. Engaging in mindfulness-based relaxation reduced the likelihood of her adrenaline taking over and acted as a stress-reducer. Unlike her tendency to go 'back to basics' after crashing in freestyle, Jade described how facing a similar situation in snowboard racing would instead encourage her to 'push herself forward' and develop a 'much more positive mindset', consciously altering her attitude and approach to the risk involved.

Focusing on Enjoyment over Competition

For Ben and Anya, adopting a realistic attitude about what was achievable in their racing career allowed them to focus on enjoyment and assisted their decision making: "I 
1 started skiing 'cause I enjoyed skiing, not 'cause I wanted to win the World Cup. So it made

2 more sense for me to take the risk not to ski race, and go to uni (Ben)."

Daisy maintained that for her, competitive results came secondary to personal

4

5

satisfaction and enjoyment; 'I think... it doesn't really matter where I come in competitions as long as I'm happy with my run and my position is like a by-product of that', explaining that her conscious attempts to uphold enjoyment and focus on being 'the best... that I physically can be, not what other people rank me as' had developed as she progressed in freestyle. Like

Daisy, Ollie's focus and skill development were not targeted at competition, but rather at selfdevelopment and enjoyment. He stated: "My ideal snowboarding is just snowboarding with my friends because it's... what makes me happy. But competing doesn't bother me. I don't mind doing it, I can quite enjoy doing it, but it wouldn't be primarily why I'm learning the tricks. I'm doing that for my own personal gain."

\section{Staying in Control}

The fourth theme illustrates how maintaining a sense of control affects participants' perception of risk and coping strategy choices, and its relationship to confidence.

Furthermore, it highlights the relationship between the athletes' confidence and expertise in their sport, and how learning (or failing to learn) from past experiences affects their strategy utilisation and preferences.

\section{Confidence and Locus of Control}

The extent to which athletes felt in control of their actions significantly affected their choice of coping strategy. Despite considering cycling to be lower-risk than skiing, Sam stated he felt 'less confident with cycling and I think that makes me take more precautions', explaining that whilst rarely wearing a helmet when skiing, he won't cycle without one because 'I worry about it more because I'm not as good at it'. Ben found his perception of risk and anxiety levels rose in higher-speed races, such as Super G and Downhill, as a 
1 successful run required letting go of control; 'you literally just point your skis down the hill,

2 and then it's up to you how fast you wanna [sic] go'. This was not a concern in slalom where

3 he felt he was on more 'familiar ground', stating 'I know what I'm capable of. It comes back

4 again to confidence [...] you can definitely feel like you have the ability to do something, and

5 most of the time you do'. Cara described how her 'stress level is kind of correlated to my

6 control'. She showed a preference to rely on ritualistic, superstitious coping strategies in

7 environments where she felt a low locus of control; 'the more I have absolutely no control

8 over what's going, on the more superstitious I become, because it's removed from

9 practicality'.

$10 \quad$ Familiarity and Self-Belief

The athletes' unanimous opinion was that competing in familiar environments reduced their perceptions of both the risks involved and their reliance on coping strategies during preparation. Heather explained how home-slopes 'don't really seem like proper dryslopes' due to their familiarity, clarifying how foreign slopes required significantly more mental preparation. Jade also felt being in 'unfamiliar territory' meant skill progression took longer, as she had to overcome 'all the different factors that are involved'.

When the athletes felt confident in their own snow-sport abilities, it reduced their sense of risk. Ollie described how he felt no anxiety in transferring his snowboarding into a racing environment, taking comfort in his ability to cope, based upon his expertise. Daisy described how waiting until she felt truly confident in her ability, helped her to master backflips on-snow: "I was with people I trusted who'd back-flipped off the same lip, I just felt confident in myself... like it just felt right? Like if stuff doesn't feel right, and if you're not doing the trick for you then I just don't do it."

\section{Gaining Self-Confidence from Others}


1 increased after observing others. For Sam, watching pro-skiers compete in the X-Games

2 allowed him to gain perspective on the level of risk he was taking; 'you just kind of feel like

3 if they can do that, then I'm sure I can just go out and do whatever it is that I wanted to do'.

4 For Cara, joining the university snow-sports team allowed her to use others as a model for her

5 own confidence; "you just think "it will be fine" and then you just kind of get on with it

6 'cause you know that these people, that these kids... that they'll end up being ok so you'll end

7 up ok'. Freddie found comfort placing confidence in the people who were in charge when he

8 engaged in the high-risk activities of snowmobiling and freestyle skiing. Ollie similarly

9 placed trust in his friend's abilities, increasing his own confidence as a result: "I'll pick a line 10 and I'll be like, mmm I'm not really sure about that... and he'll be like ach, it's good it's doable. In his eyes it's doable, so I feel like if in his eyes it's doable, it's doable in my eyes." Gaining Expertise

Heather found becoming an instructor increased her likelihood to take risks, as she believed 'you have to be willing to take the risk yourself, to see if other people can take them too'. She felt she had to become a 'role model' and set an example to others about coping with risk. She described how undertaking instructor courses had increased her skiing expertise, thus improving her ability and relaxing her attitude toward risk-taking when skiing. Ben also experienced a relationship between his confidence, perception of risk and level of Expertise: "I think the main thing for me would be the amount of experience that you have. Like, how that relates to... how confident you are, into going in to something. And the more you do it, the more your perception of risk is gonna [sic] change obviously." Learning from Past Experiences and Repeated Failure Several of the athletes used past experiences to guide their coping strategy preferences. Jade described an experience from her kite-surfing (where she experienced failure, maintained positivity and achieved a successful result), which she would reflect on 
1 during snowboarding competitions, to inform her coping style. For Ollie, learning about the

2 negative consequences of spontaneous risk-taking resulted in him increasing his planning and

3 preparation. However, Ollie also learned through repeated failure, describing his first time

4 learning rodeo-sevens (a freestyle trick) as being 'a week of just smashing my face up, over

5 and over again until like... you actually have to stop and think about it'. He emphasised how

6 his increasing expertise enlightened his risk-taking consideration in both snowboarding and

7 skateboarding; 'I'd just do stupid things [...] and now when I actually do it I make sure it's

8 possible. I used to just go for it'. The athletes utilised these past experiences from both snow-

9 based and other sports, to inform their current strategy use.

10 Underlying Influences

The final theme aimed to uncover the athletes' rationale behind their coping style preferences. As previously stated, it emerged during interviews why athletes favoured specific coping strategies, which factors influenced their preferences, and how their perceptions of snow-sports and the differences between freestyle and racing may have affected these choices. It also aimed to identify how risk and the rewards of risk-taking can act as a motivation to challenge and overcome difficulties within snow-sports.

Perceptions of the Sport

Many of the freestylers described difficulties associated with participating in a sport where they perceived performance judgements as subjective. For Daisy, the 'cool persona' required of freestyle athletes, and associated style concerns, increased her anxiety related to the opinions of others. She therefore dedicated more time to coping strategies aimed at alleviating these concerns. Sam described the increased need to focus on self-development in freestyle versus learning from coaches in racing, influencing him to opt to develop amongst friends. Ollie however found the subjective aspects of freestyle to be a stress-reducer when compared to the objectivity of racing, as he perceived poor results as being a reflection of the 
1 judges' opinions and not of his ability: “When you're doing freestyle stuff it's much more

2 relaxed and laid back because... it's subjective. I can do something that I think is nice, but the

3 judges might not think it's nice... so it's like there's not nearly as much pressure."

Both freestyle and racing athletes shared a perception of alpine racing being 'taken

5 more seriously', with Heather suggesting the elevated 'competitive edge' in ski racing

6 attributed to her perceptions of the 'pretty snobby' attitude of her fellow racers. Daisy's

7 perception of racers was of them being 'more interested in what position and stuff you came

and did you win, did you podium?', comparing this to the more relaxed attitude of freestylers,

9 who would instead inquire 'what's your best trick at the moment?'

10 Family Influence

Daisy credits her childhood attempts to impress her older brother and be seen as 'just being one of the boys' as influencing her decision to enter the 'guy-dominated sport' of freestyle skiing. For her, 'getting bashed and bruised' and pushing her capabilities in highadrenaline sport all contribute to the enjoyment. Daisy's pride in being seen as an equal to her male counterparts was also apparent in competitive settings. Thus, hearing that she had skied 'just like the boys [...] means more than getting up on the podium at the end of the day', hence allowing her to maintain an enjoyment-focused mindset, as previously described. For Cara, the influence of her father affected her choice of 'worst-case scenario' coping strategies. She described him as 'very anxious [...] always assuming that the worst is going to happen', with his constant consideration of potential dangers having 'definitely instilled that kind of anxiety in me, which is always kind of looking for the worst case'. When asked what experiences had influenced her preferred coping strategies, Heather's rationale was simply that it suited her personality: “It's just kind of the way I've always been, I've always been from a young age that sort of like annoying, hyperactive little child [...] so now when I get really nervous I'm just like gabbin [sic] away, chatting absolute rubbish." 
1 Jade also believed individuals' personality to be a contributing factor in coping strategy

2 preference, but stated that she felt extreme-sports participants to be similar in their approach:

3 'everyone has the urge and the want to do it, so they must be on some sort of similar level'.

\section{High Risk, High Rewards}

Freddie felt an integral part of freestyle skiing involved embracing risk, as 'there comes a point where you just need to kind of try and... try and go for it'. He suggested importance be placed on preparation before 'deciding that you have to go for it'. This 'gungho' attitude was repeated by Ben in reference to ski racing: If you're gonna do something, I always think you might as well do it properly. There's no point going at something if you do it half-arsed 'cause... you might as well have not done it in the first place." For Max, his primary incentive in entering competitive freestyle skiing was simply because he perceived it as 'something that was a bit of a challenge to build upon'. This suggests overcoming risk and confronting it head-on was a motivating factor for him, and he therefore consciously adopted an attitude that required him to push himself.
Discussion

This study aimed to explore an under-researched area within sports psychology; coping with risk in semi-elite snow-sports. A systematic search of the literature revealed no prior research of freestyle snow-sport athletes' use of coping strategies. Therefore, the use of a qualitative design and exploratory method was deemed appropriate to provide rich and novel data. Four of the master themes that emerged during analysis related to which aspects of snow-sport participation athletes perceived as stressful, the coping strategies they used during preparation for risk-taking, and how they utilised them. During the analytical process, it became evident that participants had provided responses related to how their perceptions of racing and freestyle influenced their rationale for their coping strategy preferences, resulting in an additional fifth theme. 
The athletes described several aspects of snow-sport participation as being potential sources of stress, and these formed the first master theme, Challenges to Overcome. Fighting against the uncontrollable elements of snow-sports often increased athletes' perception of risk. Adverse weather and unfamiliar terrain led to many dedicating more effort into using preparatory coping strategies, in an attempt to control the uncontrollable. Injury-related anxieties and concerns regarding the subsequent recovery process were identified in all ten interviews. Several participants described employing preferred coping strategies used more frequently during preparation after an injury. Therefore, it can be suggested that this sample of student athletes both require and utilise coping strategies for risk in snow-sports.

The athletes all provided rich descriptions of a variety of cognitive, behavioural and avoidant strategies, with many highlighting specific experiences that had helped identify successful strategies, resulting in a preferred coping style. Anshel (1996) describes coping styles as being reflective of an individual's tendency to respond in a predictable manner when confronted with specific situations. Participants displayed clear preferences for specific coping styles, thus this study demonstrates trait approaches to coping. Furthermore, many of the coping strategies described by the athlete could be theoretically linked to trait approach measures of coping, such as the COPE Inventory (Carver et al. 1989) and its later revisions. For example, the Changing Perspectives master theme contained first order themes related to staying positive and focusing on enjoyment over competition, which theoretically correspond to the subscales maintaining optimism and goal-replacement, from Zuckerman and Gagne's (2003) revision of the COPE Inventory. This suggests the athletes from the current study employed trait-based strategies to cope with risk, of which some could be linked to preexisting coping measures.

Conversely, many of the athletes also described examples of process coping. Often this 'on the spot' coping and deviation from their preferred strategies occurred in response to 
1 unpredictable and uncontrollable stressors. For example, dry-slope was a predictable medium

2 for many of the athletes, who had memorised every bump and rip in the mat, with jumps

3 remaining a constant size. Thus, they usually did not utilise any coping strategies whilst

4 competing on familiar dry-slopes. When competing on snow however, many found

5 themselves constantly reappraising and adapting their coping strategy use as a result of being

6 in an environment that is constantly subject to change. For example, a sunny morning may

7 change a perfectly groomed, icy slalom course into slush, requiring rapid mental and physical

8 adjustments by the athletes to cope with the constant changes. Research conducted by Hauw,

9 Renault and Durand (2008) on the acrobatic performance of elite freestyle skiers showed

10 participating athletes reported a need to be active throughout every stage of performance.

11 They described constantly making unexpected modifications and adjustments during each stage of trick execution, and relating the 'feel' of a current jump to past experiences as mental preparation for coping with the risks related to landing (see also; Anshel, 1996). Therefore, the findings of the current study suggest the participating athletes do have preferred coping styles that have stayed relatively fixed across their snow-sports careers so far. However, the unpredictable nature of snow-sports means that their preferred coping strategy may have to adapt not just from day to day, but potentially from minute to minute, as conditions change. Whilst the vast majority of coping styles described by athletes related to PFC/EFC, under certain circumstances, some of the participants displayed a preference for avoidant strategies. There were several examples of engaging in ritualistic behaviour (i.e. reciting mantras, 'touching wood') to cope with an 'uncontrollable situation'. Two participants described drinking alcohol before competitions to avoid focusing on competitive pressure, suggesting for some of the athletes involved in the current study, moderate substance use may be a preferred coping style. Roth and Cohen (1986) suggested individuals are more likely to 
1 utilise PFC styles in situations perceived as 'controllable'. The preference by some athletes

2 for avoidant coping styles may result from uncontrollable aspects of competitive snow-sports.

All the freestyle participants described how developing their skills as part of a group

4

5

significantly increased their self-confidence. Working alongside and watching others was often utilised as preferred style for coping with elevated levels of risk, such as trying something new. Sam described how just the act of watching pro-skiers compete on television was enough for him to reduce his perception of risk in his own freestyle skiing, encouraging him to push himself and try new tricks. Therefore, he gained self-confidence in his abilities from observing the confident performance of others. Often, the act of gaining self-confidence from others resulted in increased risk-taking behaviour. Therefore, its use as a coping strategy for risk could be described as a 'double edged sword'; whilst it reduces the perception of risk, it also increases the likelihood of taking higher risks.

Changing Perspectives highlighted how the athletes felt risk-taking to be an intrinsic part of snow-sport participation. For many, their considerable expertise within the sport reduced their perception of risk, allowing them to perceive it as 'normal'. A study by Albert (1999) investigated how physical risk and injury in recreational cycling could be understood as being constitutive of the sport itself, thus cyclists who participated normalised the risks presented to them as a part of their engagement in the sport, perceiving them as 'taken for granted features of participation'. Though the athletes involved in the current study arguably experience a higher level of risk within their sport participation than recreational cyclists, their attempts at 'risk normalisation' suggest this may be a strategy adopted by athletes experiencing both high and low risk integral to their sport participation.

The final theme, Underlying Influences illuminated how the perceived 'cultural differences' between freestyle and racing may influence which aspects of snow-sports are experienced as stressful, and participants' resulting coping strategy preference. Heino (2000) 
1 suggests that snowboarders view themselves as individuals who participate in the sport, not

2 for spectators or external reward, but for their own enjoyment. Snowboarding is often cited as

3 the original freestyle branch of winter-sports, and this enjoyment-focused attitude appears to

4 remain a commonality. Generally, the freestyle athletes from the current study found

5 competition stressful; the added pressure reduced their enjoyment. Thus, they tended to opt

6 for strategies related to goal-replacement, adopting the attitude that competitive results are

7 superfluous to personal satisfaction and enjoyment. This suggested lack of a 'serious attitude'

8 towards competition has even been adopted by some of freestyle ski and snowboarding's

9 most successful athletes. For some freestylers, the subjective nature of the sport increased

10 their anxiety related to the opinion of others (e.g. judges, spectators) - a concern rarely mentioned by racers - resulting in a preference for coping strategies related to alleviating these concerns. Borden's (2001) suggestion that snowboarding and therefore freestyle) culture's attempts to consciously remove itself from the 'straight society of skiing' through dramatic performances and a rhetoric of rebellion, may partly explain why some of the freestyle athletes from the present study felt more pressure to impress others and focus on aesthetics (see Edensor \& Richards, 2007).

Almost all of the racers stressed the importance of being 'organised' prior to competition, ensuring their equipment was ready and being fully prepared the night before racing. For freestylers, the use of mental imagery as a cognitive coping strategy often began weeks before an event (e.g. trying a new jump). The majority described a process of watching instructional videos, observing other athletes and mentally rehearsing movement prior to attempting a trick for the first time themselves. For racers however, mental imagery was a more immediate part of their preparation, often only utilised after course-inspection to rehearse crucial challenges just before racing. This suggests both the snow-sport race and freestyle athletes in the present study utilised coping strategies for risk and other stressors, 
1 and that their preconceptions of the differences between these snow-sports cultures

2 influenced coping style preferences.

As outlined in the introduction, there is little existing research into either coping strategies used by competitors in high-risk sports, or more specifically comparisons within snow-sports, between alpine racers and competitive freestylers or snowboarders. By taking a qualitative approach, the present study has provided a rich, in-depth analysis informing future research in this topic area. The current study explores in detail, coping strategies among highrisk competitors in snow-sports, including a range of disciplines. The study finds support for both the trait and process approaches to coping within the sample participants. The themes identified provide novel insights both into the areas of interest outlined in the introduction, as well as expanding upon the original aims of the study. Theoretical saturation was deemed to have been achieved after ten participants, as decreasing elements of new information were provided by participants in the later interviews.

Although the athletes involved in the study were considered semi-elite at university level, their participation in university competitions was often considered to be 'the beginning of the end' for their professional snow-sports careers. Furthermore, some of these athletes had no competitive snow-sport experience prior to attending university, and thus had limited competition experience to draw upon during interview. A limitation of the present study therefore is that different findings may have been obtained from a sample of elite athletes, who had elected to pursue a (semi-)professional career in snow-sports. Were the present study to be repeated, the inclusion of ski and snowboard-cross athletes would also be important, as like freestyle athletes, they remain an often overlooked athletic population within both snow-sport and wider psychology research. Furthermore, whilst the participants from the present study may be good demographic representatives of 'student athletes' it should be noted that the findings of this study may not be representative of coping behaviours 
1 in semi-elite/elite athletes, due to the small sample size and qualitative methodology used,

2 and differences between university based vs. non-university based competitive opportunities. Previous research (Lavallee et al., 1998) has suggested that athletes do utilise coping

strategies after experiencing loss and trauma within sport. The results of this study suggested that the athletes interviewed utilised both trait and process approaches to coping with experiences of both loss and trauma resulting from their engagement in high-risk sport. Many described an increase in utilising coping behaviours post-injury, and after a perceived drop in expected performance levels. Therefore, the findings of the current study reflects the preexisting literature within the coping with loss and trauma in sport field, whilst adding new understandings about similarities and differences within high-risk snow-sport contexts, and how those theories relate to strategies and behaviours reported by these competitive athletes. The findings from this study may guide coaches and practitioners in helping their athletes develop successful strategies for coping with risk and other stressors within snowsports. Frequent utilisation of coping strategies during the participants' preparations suggest that the experience of stress and need for coping strategies may be ever-present during snowsport participation, and not limited to post-injury trauma. Thus, this suggests that for snowsports athletes, the anticipation of a potential loss and/or trauma may merit the use of coping behaviours. This finding could encourage increased focus into research on the development and utilisation of coping strategies for risk as a preparatory measure. This may be relevant beyond sports to include other high-risk activities, such as improving adaptive proficiency in military personnel. Although the majority of the findings from the present study support the trait approach to coping (i.e. use of preferred coping styles), it also found evidence of process coping as a response to the unpredictability of snow-sports. Snow-sport athletes are an interesting population for future research, as the challenges they face, provide opportunities to explore how they combine and decide between trait and process approaches to coping. 
2 Albert, E., (1999). Dealing with Danger, The Normalization of Risk in Cycling. International review for the sociology of sport, 34(2), pp.157-171.

4 Anshel, M., (1996). Coping styles among adolescent competitive athletes.The Journal of

$5 \quad$ Social Psychology, 136(3), pp.311-323.

6 Bazeley, P. and Jackson, K. eds., (2013). Qualitative data analysis with NVivo. Sage

$7 \quad$ Publications Limited.

8 Bonanno, G.A., (2004). Loss, trauma, and human resilience: have we underestimated the

9 human capacity to thrive after extremely aversive events?. American psychologist, 59(1), 10 p.20.

11 Borden, I.M., (2001). Skateboarding, space and the city: Architecture and the body.

12 Carver, C.S., Scheier, M.F. and Weintraub, J.K., (1989). Assessing coping strategies: a theoretically based approach. Journal of personality and social psychology, 56(2), p.267.

Celsi, R.L., (1992). Transcendent benefits of high-risk sports. Advances in Consumer Research, 19, pp.636-641.

16 Celsi, R.L., Rose, R.L. and Leigh, T.W., (1993). An exploration of high-risk leisure consumption through skydiving. Journal of consumer research, pp.1-23. Edensor, T. and Richards, S., (2007). Snowboarders vs skiers: Contested choreographies of the slopes. Leisure studies, 26(1), pp.97-114. Endler, N.S. and Parker, J.D., (1990). Multidimensional assessment of coping: a critical evaluation. Journal of personality and social psychology, 58(5), p.844. Flørenes, T.W., Bere, T., Nordsletten, L., Heir, S. and Bahr, R., (2009). Injuries among male and female World Cup alpine skiers. British journal of sports medicine, 43(13), pp.973-978. Flørenes, T.W., Nordsletten, L., Heir, S. and Bahr, R., (2012). Injuries among World Cup ski and snowboard athletes. Scandinavian journal of medicine \& science in sports, 22, 58-66. 
1 Folkman, S. and Lazarus, R.S., (1980). An analysis of coping in a middle-aged community

2 sample. Journal of health and social behavior, pp.219-239.

3 Folkman, S. and Lazarus, R.S., (1985). If it changes it must be a process: study of emotion

4 and coping during three stages of a college examination.Journal of personality and social

5 psychology, 48(1), p.150.

6 Harvey, J. H. (1996). Embracing their memory: Loss and the social psychology of

7 storytelling. Allyn \& Bacon.

8 Heino, R., (2000). New Sports What is So Punk about Snowboarding?. Journal of Sport \&

$9 \quad$ Social Issues, 24(2), pp.176-191.

10 Lavallee, D., Grove, J. R., Gordon, S., \& Ford, I. W. (1998). The experience of loss in

11 sport. Perspectives on loss: A sourcebook, 241-252.

12 Lazarus, R.S. and Folkman, S., (1984). Stress, appraisal, and coping. New York: Springer.

13 Lazarus, R.S., (2000). How emotions influence performance in competitive sports. The Sport

14 Psychologist.

15 Nicholls, A.R. and Polman, R.C., (2007). Coping in sport: A systematic review. Journal of 16 sports sciences, 25(1), pp.11-31.

17 Rotella, R.J., Gansneder, B., Ojala, D. and Billing, J., (1980). Cognitions and coping strategies of elite skiers: An exploratory study of young developing athletes. Journal of Sport Psychology, 2(4), pp.350-354.

20 Roth, S. and Cohen, L.J., (1986). Approach, avoidance, and coping with stress. American 21 psychologist, 41(7), p.813. Sparkes, A.C. and Smith, B., (2013). Qualitative research methods in sport, exercise and health: From process to product. Routledge. coping strategies. Journal of Research in Personality, 37(3), pp.169-204. 
1 Table 1: Raw Data Themes, First Order Themes and Master Themes

2 Raw Data Themes $\quad$ First Order Themes $\quad$ Master Themes

3 - Weather and snow conditions

The Uncontrollable Elements

(1) Challenges to Overcome

4 - Variations in terrain

5 - Trying something new

$6 \quad$ Not living up to expectations

The Opinions of Others

7 - Not complying with the norm

8 - Losing time and skills to recovery

Injury and Injury Recovery

9 - Potentially life-changing injuries

10

- Financial commitments

Finding a Balance

11 - Career sustainability

12 - Planning ahead

13 - Mental Imagery

14 - Practice makes perfect

- Development with friends

Working with Others

- Modelling for technique

17 - Peer pressure

- Holding Back

Avoidant Strategies

19

- Incident first, strategy later

Limitations of Strategies

- Injuries obtained despite confidence

- Self-fulfilling prophecies

- Ignoring fear

- Confronting risks head-on

Cognitive and Behavioural

(2) Taking Action

Strategies

- Positive self-talk

- Music and meditation

- Pushing yourself

- Setting realistic goals

- Results aren't everything

Focusing on Enjoyment

Accepting Risk as 'Normal'

(3) Changing

Perspectives

29

- Locus of Control over Competition

- Familiarity

Staying Confident

(4) Staying in Control

- Self-belief

- Modelling self-confidence from others

- Becoming a role-model

Staying Positive

35 - The confidence/expertise relationship

36 - Learning from past experiences

37 - Learning from repeated failures

- Aesthetics and subjectivity in Freestyle 